\title{
Opressão Intelectual e Crítica Social: Os Sobreviventes de Uma Geração no Conto de Caio Fernando Abreu
}

\author{
Intellectual opression and social criticism: the survivors of a \\ generation in Caio Fernando Abreu's tale
}

Thays Caroline Barroca Ribeiro Morettini*

* Universidade Estadual de Londrina, Rodovia Celso Garcia Cid, Km 380, s/n - Campus Universitário, Londrina - PR, 86057-970, e-mail: thaysmorettini@gmail.com

\begin{abstract}
RESUMO: Este trabalho consiste em uma análise do conto "Os sobreviventes", da autoria de Caio Fernando Abreu (1948-1996), presente na obra Morangos Mofados de 1982. O objetivo deste estudo é desenvolver questões sobre a opressão intelectual e a crítica social evidenciadas no conto. Leva-se em conta as experiências políticas no Brasil nas décadas de 1960 a 1980. A partir desta relação entre história e literatura, verifica-se como os personagens de Caio Fernando Abreu se revelam como sobreviventes de uma geração, assolada por desigualdades sociais e pela opressão do exercício intelectual como forma de aprisionamento do indivíduo na sociedade contemporânea. O artigo parte de considerações iniciais sobre o autor e o contexto histórico das décadas de 70 a 80 no Brasil, a partir disso, apresenta-se a análise do conto "Os sobreviventes", tendo em vista a experiência da perda dos ideais desta geração, os efeitos da ditadura militar e a submissão às imposições políticas, sociais e ideológicas deste contexto. PALAVRAS-CHAVE: Opressão intelectual; Crítica social; Caio Fernando Abreu.
\end{abstract}

ABSTRACT: This work consists of an analysis of the short story "The Survivors", by Caio Fernando Abreu (1948-1996), present in the work Morangos Mofados, published in 1982. The aim of this study is to develop questions about the intellectual oppression and social criticism evident in the tale. It takes into account the political experiences in Brazil in the 1960s to 1980s. From this relationship between history and literature, it appears like that Caio Fernando Abreu's characters reveal themselves as survivors of a generation plagued by social inequalities and oppression of the intellectual exercise as a form of individual imprisonment in the contemporary society. The article is based on initial considerations about the author and the historical context of the decades 7080 in Brazil, as it presents the analysis of the short story "The Survivors" in a view of experience of the loss of the ideals of this generation, the effects of military dictatorship and submission from the political impositions, social and ideological of this context.

KEYWORDS: Intellectual opression; Social criticism; Caio Fernando Abreu. 


\section{INTRODUÇÃO}

A obra Morangos Mofados foi publicada em 1982, os contos deste livro abordam a inadaptação em um mundo em constantes modificações, neste sentido, o conto "Os sobreviventes" se torna um exemplo desta relação do homem e o sentimento de não pertencimento, oprimido por um sistema social e político dominador. Este trabalho se propõe a desenvolver uma leitura do conto "Os sobreviventes", tendo em vista o contexto histórico e cultural que o Brasil passou nas décadas de 1960 a 1970, período este marcado pela presença de uma ditadura militar, um sistema opressor que marcou a existência de uma geração assolada por desigualdades sociais e pela opressão intelectual.

O conto "Os sobreviventes" apresenta o retrato de uma geração marcada pela crise, em que o projeto de criação de um novo mundo acaba se tornando o próprio mundo em que as personagens habitam. Narrado por uma personagem feminina, a partir de uma visão de mundo irônica, o texto evoca o contexto político dos anos 60/70 do século XX no Brasil, fazendo referencia á ditadura militar.

Na narração desta personagem feminina percebe-se um discurso de resistência frente á opressão do regime ditatorial e a voz de seu companheiro, interlocutor com o qual sua fala se mescla, representa a voz de uma geração combatente aos ideias de opressão, sendo que, nada seria capaz de tirar estes personagens do abismo em que se encontram submersos, nem mesmo o exercício intelectual pode libertar estes indivíduos de sua condição de oprimidos.

A partir da análise que se fará deste conto, será possível perceber um sentimento de angústia na tentativa de modificar o presente destas personagens, as quais se apresentam ao leitor como verdadeiros sobreviventes de uma época e de um pensamento opressor. A busca por uma vida livre e alternativa se torna objeto de desejo destes personagens que se percebem como seres fragmentados em um mundo marcado por desigualdades sociais.

Neste trabalho, busca-se estudar o conto "Os sobreviventes" a partir de uma análise que evidencie uma opressão intelectual e a crítica social dirigida a um governo opressor, o indivíduo se revela como um ser fragmentado, este ser cindido que reflete a imagem do homem contemporâneo, tal fragmentação também poderá ser identificada na estrutura do texto literário, marcada fortemente pela presença do discurso indireto livre. 


\section{LETRAS}

A literatura de Caio Fernando Abreu revela um repertório de vozes de uma geração capaz de expressar suas solidões, angústias e contradições, as quais são metaforizadas pelo "mofo", termo empregada pelo autor para simbolizar uma náusea de caráter existêncial, em que a própria realidade social se torna um espaço nauseante, repulsivo.

Ao longo do conto "Os sobreviventes" é possível ver como a estrutura é visivelmente monológica, em que a voz da narradora e de seu interlocutor se misturam, a partir disso, pode-se compreender uma reflexão da personagem protagonista sobre suas angústias, medos e sonhos frustrados, percebe-se que o olhar da personagem para o passado representa um olhar retrospectivo, em que se sobressai um sentimento de derrota frente a um contexto social e político limitador de ações e pensamentos. $\mathrm{O}$ estado psicológico deste narrador-personagem também destaca ao leitor a intimidade da personagem que é capaz de revelar seu descontentamento com o presente e a dor de viver em um mundo fragmentado, em meio a ambientes opressores e preconceituosos.

Morangos Mofados foi o livro que revelou os anseios sociais de personagens que se percebem confrontadas por seus próprios ideais políticos em um período marcado pela repressão, em que a liberdade de pensamento era inibida, a censura e a perseguição política eram intensas, dessa forma, a obra de Caio Fernando Abreu constroi uma crítica de caráter social, elucidando problemas das relações entre o indivíduo e a sociedade contemporânea.

A interpretação de tal obra acaba por desconcertar o horizonte de expectativas do leitor que deve notar, sobretudo, a utilização de uma linguagem cotidiana construída a partir de fragmentos. O conjunto de contos da obra Morangos Mofados trabalha, em alguns textos, a temática do homoerotismo e, em outros, evidencia-se uma temática mais voltada para o conteúdo da repressão política. Ainda nesta obra é possível afirmar o entrecruzamentos de linguagens e estruturas formais do texto literário, no conto "Os sobreviventes", o qual inaugura este livro de Caio Fernando Abreu, pode-se identificar a presença de um caráter trágico, na medida em que se pensa a tragédia da vida destes personagens, enquanto meros sobreviventes de um período assolado por desilusões e sonhos destruídos.

Ao pensar a obra de Caio Fernando Abreu é possível inferir que o autor busca filtrar aspectos do contexto social e, a partir disso, faz uma revisitação aos valores e ideais inerentes ás sociedades conservadoras e ao sistema político autoritário vigente no período. $\mathrm{O}$ autor cria um questionamento sobre o preconceito que norteia o pensamento 
conservador, neste sentido, percebe-se que o culto aos valores tradicionais implica o reconhecimento de uma sociedade marcada por preconceitos.

A partir do reconhecimento desta crítica social, o leitor contemporâneo deve apresentar um papel engajado a fim de se inserir em um posicionamento crítico e reflexivo que permita ter uma posição frente ao contexto histórico em que se ressalta a ditadura militar e a ideologia fortemente imposta pelo conservadorismo.

\section{HISTORIA, MEMORIA E TESTEMUNHO}

A Escola de Frankfurt desencadeou um novo olhar sobre a narrativa, em que se pode destacar o rompimento com o modo clássico da criação literária, a partir desta ruptura, Theodor Adorno considera que a concepção conflitiva da realidade e do meio social em que se vive levou o escritor a revelar este aspecto em sua obra.

Adorno afirma que "Os antagonismos não resolvidos da realidade retornam às obras de arte como os problemas imanentes da sua forma." (ADORNO, 1993, p.16), de maneira que é possível compreender, em Caio Fernando Abreu, esta relação de conflito entre o homem e o meio social em que vive, isto se torna evidente na construção do texto literário, que se apresenta ao leitor como uma forma não tradicional da escrita.

Neste sentido, é válido considerar a participação ativa do papel do leitor na construção de sentidos de uma narração, isto se torna característica essencial da narrativa contemporânea, em que o leitor não mais pode ter um papel contemplativo, mas necessita ter um papel ativo na produção de sentidos da obra literária. Sendo assim, o leitor deve compreender o discurso histórico do conto de Caio Fernando Abreu, levando em conta a criação de um discurso como forma de resistência á perda da memória, assim sendo, o leitor deve criar afinidades com a matéria histórica que o conto faz alusão. A obra literária pode ser compreendida como testemunho histórico na medida em que se salienta uma relação entre o real e o fictício, dando margem para uma diluição entre o real e o ficcional, ao refletir acerca de um momento histórico e se consolidar como testemunho de uma época, a narrativa cria possibilidades para se pensar questões socias, existenciais e culturais de uma sociedade fortemente marcada pela opressão do indivíduo em um mundo contemporâneo que sofre constantes modificações.

Compreender a obra literária como testemunho de um contexto histórico específico implica considerar a linguagem enquanto um fator íntimo da voz que narra o 
texto, afinal, é a partir da linguagem que se pode perceber a relação de violência do período ditatorial, em que a identidade do sujeito da enunciação se mescla com os fragmentos de sua memória.

Ao tratar de um período histórico específico, em que a narrativa de testemunho adquire lugar privilegiado, o conto de Caio Fernando Abreu reflete fragmentos memorialísticos da personagem que se vê também como um ser fragmentado, entre passado e presente, sendo que, a possibilidade de futuro também se fragmenta, na medida em que este último é incerto e desconhecido do leitor e dos personagens.

Considerando as informações até aqui elencadas, nota-se que a compreensão do conto "Os sobreviventes" não se limita a pensar apenas o texto literário e sua literariedade, levando em conta apenas os valores estéticos e estilísticos da tessitura textual, mas, fundamental, é compreender, sobretudo, a importância de entender a formação da sociedade brasileira do século $\mathrm{XX}$, a qual se marcou por políticas autoritárias e a repressão do governo em diferentes fases dos sistemas governamentais que exerceram forte influência sobre as estruturas socias e as massas populares.

A obra Morangos Mofados pode ser interpretada como texto que representa, em seu conteúdo temático e formal dos contos, os aspectos relevantes da sociedade brasileira conservadora dos fins da década de 70, a transição do modelo ditatorial para um novo sistema político vigente capaz de moldar os valores e a conduta social dos indivíduos, opressos politicamente, socialmente e intelectualmente. Ao criar uma literatura contemporânea que reflete as nuances da história recente do Brasil, Caio Fernando Abreu tece quais as consequências destas mudanças socias no plano da esfera individual, em que o avanço da globalização e do capitalismo e seu impacto na vida do indivíduo se fazem presentes na essência da literatura contemporânea.

\section{OPRESSÃO INTELECTUAL E CRÍTICA SOCIAL: O OLHAR DE UMA GERAÇÃO}

O conto "Os sobreviventes" opera em um movimento de olhar retorspectivo, em que os personagens revisitam seus sonhos perdidos no passado, em uma tentativa infrutífera de tentar resgatá-los para o momento presente. Pode-se dizer que este olhar para o passado realizado no conto revela o testemunho de uma experiência, a qual notase ser contada a partir de um processo de fragmentação da narrativa, neste sentido, é possível considerar que o texto representa uma narrativa histórica fragmentada. 
Ao se pensar a construção estética de Caio Fernando Abreu, pode-se inferir, neste conto, que a personagem se utiliza de uma linguagem brusca e violenta, a fim de expressar seu descontentamento em relação aos acontecimentos que marcaram uma experiência pessoal traumática, as personagens se revelam, então, como verdadeiras "sobreviventes" de uma geração, marcada pela opressão intelectual. Deve-se ter em vista também que o discurso destas personagens reflete o olhar de uma geração sobre os diversos fatores sociais, políticos e econômicos que se destacaram neste período de ditadura militar no Brasil.

A protagonista do conto busca a todo o momento, em seu monólogo, ferir seu interlocutor a partir do uso de uma linguagem violenta, sendo que, as falas da personagem são marcadas no discurso predominantemente pelo uso do discurso indireto livre, o que acaba por acentuar o caráter fragmentário do texto de Caio Fernando Abreu. Neste sentido, pode-se notar como a fala da personagem protagonista é marcada por um discurso que revela sua instabilidade emocional a partir da fragmentação narrativa.

A personagem do conto "Os sobreviventes" se revela como sendo um sujeito cindido entre seus antigos ideais, os quais outrora foram reprimidos pelos acontecimentos políticos do período, verifica-se uma necessidade de adequar-se á nova sociedade, estruturada sob novos padrões capitalistas, a personagem sufoca seus desejos e vontades e suas tentativas de ação política caem por terra.

Guiada pela busca de novas perspectivas, a protagonista do conto busca uma esperança, ainda que em vão, para resolver sua vida, é importante notar que há um caráter fortemente transgressor na fala dos personagens, sendo que a opressão intelectual se revela a partir da ineficiência ou inutilidade da aplicação destas teorias nas vidas das personagens. Pode-se inferir que as correntes intelectuais ás quais a personagem faz alusão servem apenas para reforçar sua condição de ser oprimido, em uma sociedade em que as próprias ideologias se tornam o cárcere dos indivíduos.

\section{OS “SOBREVIVENTES” DO CONTO DE CAIO FERNANDO ABREU}

Os personagens do conto de Caio Fernando Abreu revelam-se como sobreviventes de uma geração assolada pela desigualdade e pela opressão, a necessidade de transformar o presente se torna uma meta, no entanto, o projeto para um futuro melhor e promissor se desestrutura com a impotência física de uma reconstrução da 
realidade social, assim, percebe-se a angústia que domina o interior da personagem narradora.

Neste conto, uma mulher faz uma revisitação ao passado político e cultural de sua geração, tendo como interlocutor seu amigo de juventude que vivenciou as mesmas coisas que esta personagem. Caio Fernando Abreu enfoca, em seu texto, o contexto político dos anos 60 a 70 no Brasil, fazendo referências á ditadura militar e ao grupos que reagiam contra este regime opressor. $\mathrm{O}$ discurso da personagem protagonista faz uma reavaliação dos acontecimentos traumáticos deste passado, em uma tentativa de compreender melhor o presente em que se encontra inserida.

Interessante é observar que a personagem decide ficar no Brasil, espaço de desilusões e sonhos destruídos nesse momento histórico, enquanto seu amigo decide partir para Sri-Lanka, assim, afirma a personagem de Caio Fernando Abreu: "Quanto a mim (...) fico por aqui mesmo comparecendo a atos públicos, pichando muros contra usinas nucleares, em plena ressaca (...) ao fim de mais outra semana de batalhas inúteis" (ABREU, 2005, p. 25)

Neste discurso, evidencia-se uma voz que desvaloriza o futuro a partir das ações realizadas no presente, ao se pensar o discurso da personagem feminina, verifica-se um tom de resistência em relação á situação em que se encontram, já, o discurso da personagem masculina expressa suas desilusões, em um tom de desistência.

Pode-se perceber que, neste diálogo, não há a esperança de uma melhoria da vida da personagem, não há escapatória, o personagem entra justamente em desacordo com o mundo e com o tempo-espaço em que se encontra: "Não tem jeito, companheiro, nos perdemos no meio da estrada e nunca tivemos mapa algum, ninguém dá mais carona e a noite já vem chegando". (ABREU, 2005, p.29)

Os personagens do conto de Caio Fernando Abreu realizam um movimento de olhar para o seu passado histórico, revisitando acontecimentos marcantes em uma tentativa de reorganizá-los no presente, desta forma, os personagens conseguem atribuir sentido para suas experiências no presente, seguindo um rumo para um futuro desconhecido. Assim, o conto se aproxima da noção de testemunho histórico, em que a voz da personagem protagonista revela uma narrativa fragmentada, onde a linguagem se apresenta ao leitor como parte de uma experiência traumática sofrida pela protagonista do conto.

Este caráter fragmentário da narrativa indica a necessidade de uma maior atenção no processo de leitura, pode-se identificar esta narração como um monólogo 


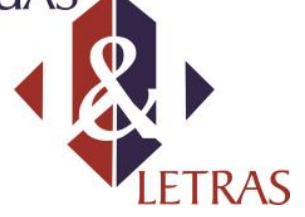

entrecortado que revela as experiências traumáticas da personagem. Nesta narrativa monológica não é possível perceber uma linearidade dos fatos decorrentes, isto acaba por revelar um traço da instabilidade emocional da protagonista de "Os sobreviventes".

A fala da protagonista expressa um tom de acusação contra o amigo, de forma que a crença de que, simplesmente ao mudar o país, isto poderia preencher o vazio que as experiências antigas haviam deixado. Ainda é possível perceber que a personagem tem consciência de suas frustrações, buscando encará-las a fim de encontrar um meio de superação para os traumas vividos outrora em seu passado.

Pode-se compreender esta personagem como sendo um indivíduo fragmentado entre o presente marcado por desilusões e o passado, de antigos ideais aniquilados e reprimidos em uma tentativa de adequação ao novo, á uma nova ordem burguesa que surge como manifestação de um progresso capitalista em efervescência.

Em “Os sobreviventes”, o mundo não representa uma imagem agradável sobre o futuro, a identidade dos personagens em meio a este mundo contemporâneo permanece imprecisa, tanto no presente assim como no futuro, a interioridade do personagem revela um ser desajustado. Em seu discurso elabora-se uma transgressão de sua imagem pessoal, ao afirmar: "ora não me venhas com autoconhecimentos-redentores, já sei tudo de mim, tomei mais de cinqüenta ácidos, fiz seis anos de análise, já pirei de clínica lembra?" (ABREU, 2005, p.27)

A fala da personagem protagonista marca sutilmente como sua descrição de si mesma subverte a imagem de um indivíduo que possui um ideal, em sua fala, a personagem afirma que nega o ideal e, dessa forma, percebe-se a libertação da personagem deste contexto de opressão política e intelectual, em que o indivíduo se torna livre para o fracasso

Ah não me venha com essas histórias de atraiçoamos-todos-os-nossosideais, eu nunca tive porra de ideal nenhum, eu só queria era salvar a minha, veja só que coisa mais individualista elitista capitalista, eu só queria era ser feliz, cara, gorda, burra, alienada e completamente feliz (Abreu, 2005, p. 27).

$\mathrm{Na}$ medida em que a personagem se torna livre para fracassar, pode-se questionar aqui sobre a que ponto a liberdade intelectual se torna uma virtude ou algo pernicioso para o indivíduo na sociedade contemporânea. No livro Modernidade líquida (2001), Bauman se pergunta acerca deste conceito de liberdade, questionando como a liberdade pode representar um ideal de maldição, o autor pergunta: “A libertação é uma bênção ou uma maldição? Uma maldição disfarçada de bênção, ou uma bênção temida 


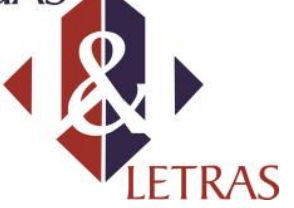

como maldição?" (BAUMAN, 2001, p. 26). Mais a frente o próprio Bauman responde a suas indagações, ao afirmar que: "A verdade que torna os homens livres é, na maioria dos casos, a verdade que os homens preferem não ouvir.” (BAUMAN, 2001, p. 26)

A partir desta discussão sobre a liberdade intelectual, torna-se importante pensar, especialmente, o modelo do percurso intelectual desta narrativa de Caio Fernando Abreu, em que se percebe a divisão dos membros desta sociedade em conformados e inconformados, percebe-se a existência de indivíduos em conflito com sua sociedade, estes personagens excluídos e, por assim dizer, exilados dos privilégios e do poder, assim como afirma Edward Said em sua obra Representações do intelectual (2005)

Mesmo os intelectuais que são membros vitalícios de uma sociedade
podem, por assim dizer, ser divididos em conformados e
inconformados. De um lado, há os que pertencem plenamente à
sociedade tal como ela é, que crescem nela sem um sentimento
esmagador de discordância ou incongruência e que podem ser
chamados de consonantes: os que sempre dizem "sim"; e de outro, os
dissonantes, indivíduos em conflito com sua sociedade e, em
consequência, inconformados e exilados no que se refere aos
privilégios, ao poder e às honrarias. (Said, 2005, p.60)

Considerando o excerto acima, é possível considerar que a personagem protagonista do conto "Os sobreviventes" representa a figura de um intelectual que se projeta à margem da sociedade, em uma condição de exílio intelectual, seu discurso revela que as ideologias dominantes em seu passado, tais como o marxismo, a psicanálise, a libertação pelas drogas e livre expressão sexual, representam formas de pensamento que não são mais capazes de libertar a personagem de sua situação atual, assim a protagonista se vê como um ser vazio em busca de suas "ilusões perdidas".

Seguindo ainda a linha teórica de Edward Said, a respeito das representações do intelectual em diferentes sociedades, o estudioso considera a importância de como o esforço intelectual se expressa na política de uma sociedade, o autor afirma que a política está em toda a parte e é justamente por este fato que s intelectuais sempre pertencem ao seu tempo, neste sentido, é possível evidenciar como a protagonista do conto de Caio Fernando Abreu representa este intelectual desiludido em preso ao seu tempo, sendo que a personagem sofre com a solidão de sua condição de exilado. Isto se torna evidente ao pensar como o passado da protagonista revela um histórico de opressão política dominadora de uma sociedade capitalista em ascensão.

Seguindo a linha teórica desenvolvida por Edward Said, a autora e estudiosa Beatriz Sarlo, em Cenas da vida pós-moderna (1997), elenca algumas tarefas dos 


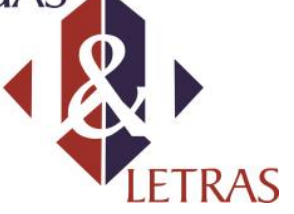

inetlectuais nas últimas décadas. Sarlo considera que

\begin{abstract}
Algumas funções que essa figura considerava suas continuam a ser reclamadas por uma realidade que mudou, mas nem tanto a ponto de tornar inútil o que foi o eixo da prática intelectual nos últimos dois séculos: a crítica daquilo que existe, o espírito livre e anticonformista, o destemor perante os poderosos, o sentido de solidariedade com as vítimas. (Sarlo, 1997, p.165)
\end{abstract}

Para Sarlo, a mudança operada na realidade faz refletir sobre o resultado do exercício intelectual dos últimos tempos, dialogando com o argumento de Said sobre conformistas e inconformistas, a estudiosa reclama a função da crítica cultural e expõe como a arte deve ser considerada uma atividade reflexiva, o que se percebe nitidamente no conto "Os sobreviventes", a construção de uma literatura engajada faz com que o leitor possa refletir sobre o contexto histórico e político de uma geração em um olhar retrospectivo, o mesmo olhar criado pela protagonista do conto.

Para além de pensar a configuração do intelectual neste conto, pode-se perceber que há no discurso da personagem de Caio Fernando Abreu um processo de desconstrução de sua própria identidade, em um tom de desabafo em que seu discurso se projeta como uma confidência ao leitor, até que a própria personagem possa conceber a possibilidade de um novo futuro, um início a ser recomeçado.

A fim de pensar a ausência de linearidade do conto, como já se notou, a narrativa é fragmentada devido à instabilidade emocional da personagem, verifica-se que a experiência pela qual a protagonista passa é traumática e frustante, isto torna sua fala desconexa, a respeito da instabilidade deste narrador, pode-se afirmar que a não linearidade do conto perturba o leitor, assim como considera Porto (2005)

O narrador de "Os sobreviventes" é instável e perturba o leitor ao dificultar a identificação de vozes e também ao abolir os princípios da lógica convencional de narração segundo a qual os fatos são apresentados ao leitor de acordo com os princípios de início, meio e fim e de disposição linear das falas. (Porto, 2005, p. 93)

Em diversos fragmentos do conto "Os sobreviventes" pode-se notar o aniquilamento dos ideais do indivíduo, reprimido pelos acontecimentos políticos e tentando se adequar a uma nova ordem social. A protagonista do conto se vê obrigada a sufocar seus desejos e suas ações políticas, em que o consumo se revela como uma alternativa para enganar as experiências frustadas. No excerto que segue abaixo é possível compreender essa relação do homem com a mercadoria, símbolo máximo do capitalismo, além da representação do espaço urbano como local que viabiliza a 


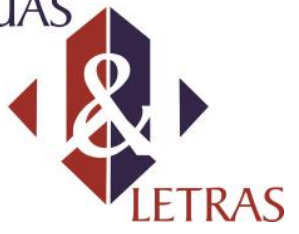

degradação das relações humanas, estas são substituídas pelo valor do capital.

Quanto a mim, a voz rouca, fico por aqui comparecendo a atos públicos, entre uma e outra carreira, pixando muros contra usinas nucleares, em plena ressaca, um dia de monja, um dia de puta, um dia de Joplin, um dia de Tereza de Calcutá, um dia de merda enquanto seguro aquele maldito emprego de oito horas diárias para poder pagar essa poltrona de couro autêntico onde neste exato momento vossa reverendíssima assenta sua preciosa bunda e essa exótica mesinha de centro em junco indiano que apóia vossos fatigados pés descalços ao fim de mais uma semana de batalhas inúteis, fantasias escapistas, maus orgasmos e crediários atrasados. (Abreu, 2005, p. 13 - 14)

A protagonista do conto indica ao leitor, em seu discurso, sua própria posição intermediária entre o questionamento ao passado e a submissão à nova ordem burguesa que se instaura na sociedade brasileira do período. Para se adequar ao novo ambiente social em que vive, a personagem precisa incorporar os valores da nova sociedade, sendo que, a partir deste conflito, a protagonista poderá ir em busca de novas perspectivas ideológicas para contornar sua situação, ainda é importante notar que a personagem cita algumas figuras intelectuais, tais como Marx, Marcuse, Reich, Castañeda; dentre outros. A respeito da presença destes intelectuais na fala da protagonista, Porto faz considerações relevantes para se pensar a simbologia destas personalidades em um contexto capitalista, dominado pelos ideais das regras de mercado.

É extremamente interessante a relação dos personagens com os autores que citam: Marx, Marcuse, Reich, Castañeda, Laing. Marx critica o capitalismo, o valor de uso e de troca instaurado em sociedades capitalistas, opondo-se a uma ideologia dominante que perpetua as regras do mercado. Marcuse é um dos membros da Escola de Frankfurt, tem estudos na área da psicanálise e seu pensamento engloba a defesa de transformações revolucionárias tanto nas instituições sociais como nas atitudes do homem (inclusive na questão da sexualidade), o qual deve se livrar de convenções que o controlam. Reich é também da área da psicanálise, acredita que o orgasmo tem papel político e defende a idéia de que a revolução social só é possível através da revolução sexual. Castañeda está ligado ao universo das drogas e defende a libertação do pensamento tradicional, propondo interpretações alternativas do mundo. (Porto, 2005, p. 101-102)

Nota-se que a voz da protagonista de "Os sobreviventes" clama pela formação de uma mentalidade centrada nos ideais de liberdade e igualdade. Verifica-se que a opressão intelectual pode ser visualizada a partir de um olhar sobre as décadas anteriores, em um olhar retrospectivo do passado para o presente.

Assim, nas décadas de 60 e 70, foi possível evidenciar os valores de liberdade cultural e sexual, a partir de movimentos de contracultura, no entanto, estes valores 


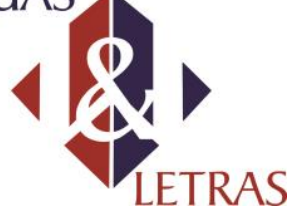

serão sufocados pela geração precedente, os anos 80 vivenciou o fim de uma opressão política e a instauração de um novo regime autoritário, baseado na ditadura do capital. A partir deste percurso, é possível perceber também a frustação intelectual da personagem que passa a perceber que nenhuma leitura é suficiente para tirá-la da situação frustrante em que se encontra, as ideologias caem por terra e só o que resta é o gosto amargo do fracasso e da derrota como ser humano.

Já li tudo, cara, já tentei macrobiótica psicanálise, drogas acupuntura suicídio ioga dança natação cooper astrologia patins marxismo candomblé boate gay ecologia, sobrou só esse nó no peito, agora o que faço? [...] em cada canto do meu quarto tenho uma imagem de Buda, uma de mãe Oxum, outra de Jezuzinho, um poster de Freud, às vezes acendo vela, faço reza, queimo incenso, tomo banho de arruda, jogo sal grosso nos cantos [...]. (Abreu, 2005, p. 15)

Apesar das desilusões da protagonista, ao final do conto é possível perceber a necessidade de se ter esperança para construir um novo começo, ao reconhecer o vazio que o presente deixa em seu interior, a personagem percebe, finalmente, que a única coisa que lhe resta é um futuro sem perspectivas concretas.

Te desejo uma fé enorme, em qualquer coisa, não importa o quê, como aquela fé que a gente teve um dia, me deseja também uma coisa bem bonita, uma coisa qualquer maravilhosa, que me faça acreditar em tudo de novo, que nos faça acreditar em todos de novo, que leve para longe da minha boca esse gosto podre de fracasso, de derrota sem nobreza [...].” (Abreu, 2005, p. 17)

Por fim, percebe-se a necessidade da personagem de resgatar em seu passado o sentido de sua existência para que ela e seu companheiro possam sobreviver a um presente marcado pela opressão social, cultural e intelectual. O vazio deixado pelas desilusões do passado e a instabilidade do presente representam um legado de frustações e misérias que levarão ambos os personagens a construir o seu futuro como sobreviventes.

Ao concluir este estudo, é relevante considerar como a literatura de Caio Fernando Abreu apresenta-se ao leitor como uma literatura engajada, em que os questionamentos sobre o contexto histórico e político das décadas de 60 a 70 e do começo dos anos 80 possibilitam perceber como o autor pautou as discussões sociais deste cenário político, o que viabilizou o questionamento sobre os valores e ideais dos sobreviventes de uma geração. 


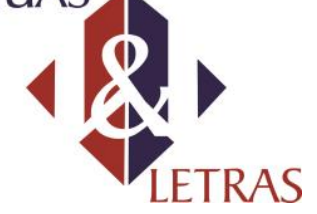

\section{CONSIDERAÇÕES FINAIS}

Com a realização do presente estudo foi possível perceber, a partir desta relação entre história e literatura, como os personagens de Caio Fernando Abreu se revelam como sobreviventes de uma geração, assolada por desigualdades sociais e pela opressão do exercício intelectual como forma de aprisionamento do indivíduo na sociedade contemporânea.

Notou-se como a opressão intelectual assolou a vida destes personagens e marcou toda uma geração, neste sentido, opera-se uma crítica em relação á experiência da perda dos ideais pela geração dos anos 60 a 70, os efeitos da ditadura militar e a submissão ás imposições políticas, sociais e ideológicas deste contexto.

Ainda foi possível perceber como a fala da protagonista revela um olhar retrospectivo, marcado pela necessidade de reviver os ideais de uma geração, de forma a criticá-los socialmente em um contexto político assolado pela opressão intelectual do indivíduo. O passado destas personagens é narrado em um texto fragmentado, em que se pode evidenciar como a fragmentação do indivíduo e o não pertencimento ao meio social se mostram como elementos caracterizadores deste modo de narrar cindido.

A voz da personagem resgata os sonhos perdidos de sua geração, para que eles não se deixem cair no esquecimento, no momento presente em que se está narrando a história, ao reavivá-los em sua narrativa, a personagem viabiliza pensar em uma maneira de sustentar a angústia provocada por um vazio do existir.

A experiência da violência é também evidente no texto de Caio Fernando Abreu, tendo em vista a linguagem empregada pelo autor, que optou pelo uso de uma linguagem cortante e violenta, que representasse de fato a dor e a angústia de uma geração oprimida intelectualmente e socialmente. Através desta linguagem violenta, o autor demonstra em seu texto como se expressam a violação da autonomia do sujeito, da liberdade individual e da liberação sexual, ideais estes que foram vivenciados pelo desenrolar de acontecimentos históricos que marcaram esta geração. Desta forma, foi possível perceber como a narrativa traumática do conto "Os sobreviventes" simboliza um contexto de época em que as personagens se revelam, sobretudo, como sobreviventes de uma geração, de um período histórico e, principalmente, sobreviventes de sua própria existência. 


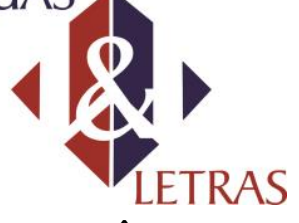

\section{REFERÊNCIAS}

ABREU, Caio Fernando. "Os sobreviventes" In: Morangos Mofados. Rio de Janeiro: Agir, 2005.

ADORNO, Theodor W. Teoria Estética. Lisboa: Edições 70, 1993.

BAUMAN, Zygmunt. Modernidade Líquida. Rio de Janeiro: Jorge Zahar, 2001.

PORTO, L. T. Morangos mofados, de Caio Fernando Abreu: fragmentação, melancolia e crítica social. 2005, 161 f. Dissertação (mestrado em literatura brasileira) - Faculdade de Letras, Universidade Federal do Rio Grande do Sul, Porto Alegre.

SAID, Edward. Representações do intelectual. São Paulo: Companhia das Letras, 2005. SARLO, Beatriz. Cenas da vida pós-moderna: intelectuais, arte e vídeo-cultura na Argentina. Rio de Janeiro: Editora UFRJ, 1997.

Data de recebimento: 19/04/2016

Data de aprovação: 28/11/2016 